\title{
Study on Teaching of College English Translation based on Translation
}

\section{Ethics}

\author{
Lihong Zhang ${ }^{1}$ \\ ${ }^{1}$ School of Foreign Language Education, Liaocheng University, Liaocheng, Shandong, 252059
}

Keywords: English Teaching; English Translation; Translation Ethics; Countermeasures; Measures

\begin{abstract}
In the English study, more and more emphasis on English language translation capabilities. Almost all the major, almost opened the English translation teaching. However, the effect is unsatisfactory. English translation is not only the pursuit of fluent language, semantic logic is reasonable and it is to follow the ethics of translation. In these various requirements in the relationship between stress translator for self and others, and to strengthen ethics training teachers translation has reached a critical juncture imminent, this paper aims to raise questions about the present stage of English teaching, combined with translation ethics important when teaching resistance, propose appropriate countermeasures.
\end{abstract}

\section{Introduction}

Translation ethics, science-based translation, the translation is the conversion of two or more languages. Conversion between languages, we have developed many theoretical system and methodology. In the most well-known in the guidelines, in simple terms, we pursue "the letter, Elegance" translation standard, faithful to the original, the statement fluent, and the pursuit of the beauty of language translation. However, sometimes the traditional translation theory has been unable to meet the growing demand for translation and translation standards. As many unexplained phenomena, the traditional translation theory is also suffering from the academic question. In translation, the translation relates to multi-party relations. The first is the relationship between translators and translation of text, translators and furthermore is writer relationship. Moreover, it is cultural exchange and conflict between the two countries and nations. In these complex multi-party relationships, the translator has to keep a clear mind is a very easy thing. Therefore, the translation of the concept of ethics, gradually been raised. It has become a research direction of translation of an inevitable trend. Due to the diversity of the translation object, fidelity also guarding the great challenge of translation, confined to pursue the original objectives have been no longer satisfied with the complex reality of the situation. Translation ethical worth is the emphasis on translators in these various requirements for self and relationships with others. Translation should communicate with others for the purpose of the requirements for translators is increasing. We need translators in the translation process, not in the creation of a separate text, but rather to ensure truthful author ideas and the central idea. This requires a higher staff translated literary accomplishment and professional ethics. Translation ethics related to translation studies and the combination of the two disciplines of ethics in the practice of translation, research ethics is how the specific impact of translation activities. Translator is really great responsibility, not just a simple translation of a 
literary work, but in reality is a cultural transmission angel to cultural works from other countries to pass national. It plays a very important role in the dissemination of culture and communication. Therefore, more should translate ethics to regulate the moral qualities of translators, handling their own good relations with others in the translation process. In colleges and universities, the dissemination and practice of translation ethics are the teacher, and the teacher's role in the meantime unusual.

\section{The Responsibilities of College English Teachers}

Teachers, they should not only shoulder the responsibility of educating the younger generation, but also pay attention to their moral ethics construction. Therefore we can say College Translation Ethics Building from the culture of individual teachers first have to translate ethics begins. According to the definition of translation ethics may know, the most important requirement is faithful to the original, stay awake. In this case the teacher's role is very important, not only to clear himself, but also shoulder the responsibility to guide students. The following three aspects will be explained during the translation ethic building should pay attention to several aspects.

Our major colleges and universities, teachers matter plays a crucial role. One reason is the level of teachers, the school decided that a level of quality, and even can decide the level of education of a student, the impact of student life. Therefore, teachers colleges and universities own efforts to improve their professionalism. Enhance academic research capacity in teaching can make their own unique insights. Translation ethics construction lay a good foundation.

English teachers in colleges and universities as a cultural communicator in different countries, should first deal with their cultural relations with other countries, due to the spread of foreign cultures in the process, it should first show its position. We can not fall into the "national nihilism" in the whirlpool. Furthermore, when performing broaden students' international perspective, in fact, it did the spread of effect of foreign cultures, and in this process, a part of college English teachers should resist the decadent foreign culture, and to spread positive rich cultural content, national culture and modern society to learn language translators. So as to promote the development of national exchanges, especially the spread of culture.

English Teachers College is not just simply teach students knowledge, but students should take responsibility and moral consciousness of a person if there is no moral level, it would be extremely dangerous to society people. Teacher professionalism and expertise in this play an important role in this, but it is need to regulate the ethical, to meet the cultural needs of the students. College English teachers should take this responsibility, and constantly explore find English teaching skills, adhere to the students good ethics and truth Translation Ethics. Therefore, to establish students' moral awareness is the most important responsibility.

\section{The Current College English Translation Teaching}

While in the country now we have opened many English professional translation courses, but significantly less than other types of courses. In non-English majors among English teaching still remain in the traditional mode of education. In the classroom teachers with English translation of attitude it is not very positive, mostly in the teaching plan does not translate directly into the culture as the ability to improve students' English proficiency programs. This attitude led directly to the students' translation is not treated very seriously. 
Translation Teaching has always been a headache for English teachers teaching content, because they require specialized knowledge of English reserve large enough. Both for listening, speaking, writing ability requirements are high. But now EFL Teachers can also have these capabilities are very few people, let alone a man versed in this area. Most English teachers do not have the experience of studying abroad, as well as by Chinese traditional education therefore, cause these problems. The same teacher in translation ethic does not necessarily how deep understanding.

School teaching content will generally depend, teacher teaching program is based on teaching materials planning. Since the beginning of the implementation of the reform of college English, English education in universities across the country are full of vitality, in order that students can learn more pure English, various colleges and universities have adopted their own textbooks written textbooks change from the beginning of our European and American universities several well-known English textbooks. These textbooks are basically no introduction to the translation ethics. Therefore, teachers should be combined with their own reality and the reality of translation ethics to explain.

Traditional translation teaching is generally first look for an elegantly written article for students to focus on the words and the words to explain the difficulties, the students then translated the last teacher to explain. Translation ethics teaching is for students with little or no content. After such a long way to educate students, students can enhance certain translation capabilities, but students are not a good mix of all aspects of the knowledge learned to practice, meaning the final translation will not be carried out as much, and even lead to students translation ethics distorted, producing bad results. Traditional English translation teaching more focused on the student's ability of taking and teaching English in everyday which was very lacking, students tend to only translate a very narrow face and not on the various aspects of English life were smooth and accurate translation. Among the translation-oriented education is the ability to exercise the students in Translation, if simply translated into Chinese to English, students can do, but if the students to translate Chinese into English by a lot of people to worry.

\section{The College English Translation Teaching Strategies}

College English translation teaching strategy boils down to improve teaching, teachers should be teaching how to translate in the future, should not only pay attention to this own translation of ethical responsibility, we also need to do the following:

Carrying students to translate ethics education, students should pay attention to the practicality of translation ethics education rather than those metaphysical ethics education should focus on teaching theoretical framework and literature character class papers, reports and other useful literature class at the same time teaching do not forget the students literary ethics and passion for literature.

Teachers should change the original strategy to explain, explain more translation phenomenon, Yan Fu translated as some phenomenon, the phenomenon of Lin's translation, there is translation skills to summarize and explain summarized. Teachers explain when this knowledge in order to enhance the interest of students should take a variety of methods and measures, such as increasing class rich content, and more to supplement curricular content. In addition, the translation techniques also require teachers to explain, in the classroom to add more to explain the knowledge to help improve students' translation speed and accuracy of translation. For the students, the teacher to explain whether students understand a lesson plays a very important role. 
Familiarity with the text of the decision is based on the length of time, the number of students practice exercises in the classroom, the more proficiency naturally increases. Traditional College Translation Teaching Practice content is generally placed in the teacher after class, students have led to slack lazy move, which reach very good results. Teaching and practice, and only after students in learning theory, while personally practice can learn to translate its laws in order to improve the corresponding theoretical methods and techniques. In which the role of teachers is to provide better error correction analysis and urge the students for students. Only continue to learn new teaching methods in order to provide better support for the theory of translation teaching.

Translation is one of the important conditions for transport out of every language, learning a foreign language in today's society mainly wants to have their own place, and therefore can learn a good translation will become one of the conditions essential. First, college students are mostly engaged in translating these areas: science and technology, law, journalism and other cultural and sports aspects of translation, stylistic differences directly affect the student's translation speed and accuracy. How to find some of the rules and methods to distinguish between these different stylistic, which requires students to have a good sense of style. Language is the carrier of culture, languages and cultures mingled indispensable. In the long-term teaching culture, we should develop students' cultural awareness, a country, a nation has its own language, they want to learn a language well must first learn about their culture.

\section{Conclusion}

Teachers should be teaching during the same time continue to increase their knowledge and develop good ethics translate. Translation of the ethical requirements set out not too much, but the translation Ethics Training College Translation Teaching and the teachers are already joined at the hip. All in all, want to strengthen the level of students 'English translation, was bound to strengthen teachers' knowledge of literacy. We want to train translators socially useful, not only cooperation between teachers and students, but also the need for government support. The only way to develop a strong professional is with excellent translation of ethical consciousness of college students.

\section{REFERENCE:}

[1] Cai Jigang. Emphasis on college English translation teaching to enhance students' English proficiency [J]. Chinese translation, 2003, (1): 63-66.

[2] Gao Limin. Stylistic Features of Business English and their translation [J]. Chinese Science \& Technology Translators, 2013, (2): 36-44,58.

[3] Gong Huiling. Problems and Countermeasures in College English Translation Teaching [J]. Foreign Languages Teaching, 2009, (2): 44-48.

[4] He Sanning. Concept Training Translation Teaching awareness [J]. Shanghai Translation, 2008, (4): 55-58. 